\title{
Health check-ups of children living in a Belarus district contaminated after the Chernobyl accident
}

\author{
C. Luccioni ${ }^{1,2 \star}$, O. Kornevich ${ }^{3}$, A. Rozhko ${ }^{4}$, V. Averin ${ }^{5}$, S. Kanada ${ }^{3}$, V. Yauseyenka ${ }^{4}$, O. Krivko ${ }^{3}$, \\ D. Laurier ${ }^{1}$, P. Pagès ${ }^{6}$, T. Zhunussova ${ }^{7}$, S. Charron ${ }^{1}$, J.-R. Jourdain ${ }^{1}$, L. Joukowskaya ${ }^{5}$, F. Rollinger ${ }^{1}$, \\ D. Franck ${ }^{1}$, C. Maccia ${ }^{6}$ and J. Tretiakova ${ }^{8}$ \\ 1 Institute for radiological protection and nuclear safety (IRSN), Fontenay-aux-Roses, France. \\ 2 Conservatoire national des arts-et-métiers (Cnam), Paris, France. \\ 3 Chechersk central hospital, Chechersk, Belarus. \\ ${ }^{4}$ Republican research center for radiation medicine and human ecology (RRCRM\&HE), Gomel, Belarus. \\ 5 Research institute of radiology (RIR), Gomel, Belarus. \\ ${ }^{6}$ Centre for quality assurance of health technological applications (CAATS), Bourg-la-Reine, France. \\ 7 Norwegian radiation protection authority (NRPA), Østeras, Norway. \\ 8 Fert, Minsk, Belarus.
}

Received 7 April 2015 - Accepted 8 April 2016

\begin{abstract}
The Chernobyl nuclear accident, which occurred on April 26th, 1986, resulted in widespread long-term contamination, mainly due to ${ }^{137} \mathrm{Cs}$, of large territories where populations live. A project was initiated to assess the ${ }^{137} \mathrm{Cs}$ body burden and health status, not limited to radiation-induced pathologies, for all children living in a highly contaminated district in Belarus; the aim was to provide detailed information for parents worried about their children's health, without the intention of quantifying the radiation-induced risk. In total, about 2500 children benefited from these check-ups, which included approximately 30 parameters and were repeated three times between 2005 and 2009. The internal ${ }^{137} \mathrm{Cs}$ burden was rather low; about $50 \%$ of children had less than $10 \mathrm{~Bq} \mathrm{~kg}^{-1}$. The health indicators reported in this paper are the global health status, physical development, and frequencies of thyroid modifications and cardiac dysfunctions. The ${ }^{137} \mathrm{Cs}$ body burden or density deposition did not appear to be strongly associated with these health indicators; other parameters, such as quality of living conditions and rural or urban residence, appeared to be more important. The aim of the project was achieved, as the results provided a global overview of the health status and level of internal contamination of children living in a contaminated territory about 20 years after the accident.
\end{abstract}

Keywords: Chernobyl / contamination, environmental / children / health impact / contamination, internal

\section{Introduction}

The Chernobyl nuclear accident, which occurred on April 26th, 1986, resulted in a prolonged release of large quantities of radionuclides to the atmosphere, and therefore in widespread contamination of large territories, mainly in Belarus, Ukraine and Russia, with Belarus being the most impacted country due to meteorological conditions (UNSCEAR, 2008).

Among the radionuclides released, short-lived ones, such as iodine, quickly disappeared, but others, mainly ${ }^{137} \mathrm{Cs}$ out of the exclusion zone (the area within a $30-\mathrm{km}$ radius centered on the location of the Chernobyl reactor), had longer half-lives, resulting in long-term contamination. About 115,000 inhabitants were relocated but a large population still lives in areas with a ${ }^{137} \mathrm{Cs}$ deposition density above $37 \mathrm{kBq} \mathrm{m}^{-2}$.

\footnotetext{
* catherine.luccioni@lecnam.net
}

Taking into account the difficulties of living in long-term contaminated territories, the $\mathrm{CORE}^{1}$ program was launched in 4 districts (Bragin, Chechersk, Slavgorod and Stolyn) of the Republic of Belarus, with 4 priority areas: healthcare and surveillance, radiological quality, economic and social development in the rural contaminated areas, and culture and education of children and youth/transmission of the memory of the Chernobyl accident (CORE, 2004).

In this program, the IRSN took the lead of the development of a healthcare project with Belarusian, Norwegian and French partners. Before initiating this project, meetings were organized with the inhabitants of the contaminated territories; they highlighted that the recurrent worry expressed was related to child health, with a general feeling that it had deteriorated

${ }^{1}$ COoperation for REhabilitation of living conditions in Chernobyl-affected areas in Belarus. 
since the Chernobyl accident and that all health problems were due to radiation exposure. Health professionals described an increase in various pathologies or dysfunctions, but they had no detailed data. Many epidemiological studies of health effects attributable to radiation exposure due to the accident were performed. They demonstrated an increased risk of thyroid cancer among individuals exposed to radioactive iodine during childhood at the time of the Chernobyl accident, as well as an excess risk of leukemia associated with the dose received by liquidators (UNSCEAR, 2011; Zablotska et al., 2011, 2013). Many other health effects have been suggested as consequences of the accident, but the diversity of observations and the methodological limitations of most studies did not allow drawing coherent conclusions. In peer-reviewed scientific literature, there are few data about the health effects of chronic exposure to ionizing radiation; today, many questions still persist about the health impact for the local populations of the radioactive contamination consecutive to the Chernobyl accident. Thus, it was impossible to provide inhabitants with solid scientific answers.

Therefore, it was decided to initiate a project to assess the health status and internal exposure of children living in a contaminated area, relying on the expertise of local professionals and current practices in the field of health check-ups. It was decided to implement the project in the Chechersk district, being one of the most contaminated, with a large number of children and an efficient proactive health system.

Children included were born at least several years after the accident and therefore were only exposed to chronic exposure due to long-lived radionuclides and not to radioactive iodine. The aim of the check-ups was essentially descriptive, with no intention of quantifying the radiation-induced risk.

Therefore, few statistical tests were performed regarding the potential causes of the observed variations of health indicators. The medical check-up was intended to be complete, without predefined etiological hypotheses and not being focused on potentially radiation-induced pathologies. Besides specific Belarusian parameters (health groups, school maturity, physical development, medical groups for physical training, etc.), the data collected included standard items such as eating habits, height and weight, palpation, cardiopulmonary examination, psychomotor development, biological tests (blood cell counts, serum iron, glucose, urinary biochemical tests), pathologies identified before and after the health check-up, electrocardiogram and, if justified, cardiac and/or thyroid ultrasound examination.

This paper summarizes the methodology of the study and presents some results of the check-ups: the ${ }^{137} \mathrm{Cs}$ internal body burden and some health indicators.

\section{Methodology}

\subsection{Characteristics of the Chechersk district}

It is situated in the north of the Gomel region and occupies a territory of over $1,200 \mathrm{~km}^{2}$. The population is about 16,000 , with 9,600 living in Chechersk city, which is the only town in the district (urban area); all other inhabited localities (93) constitute the rural area.
The ${ }^{137} \mathrm{Cs}$ deposition density pattern, established from extensive monitoring of the affected territories, is highly inhomogeneous, with the deposition density being above $1,500 \mathrm{kBq} \mathrm{m}^{-2}$ in some areas (Figure 1).

In the contaminated territories of Belarus, five zones of residence (A to E) were identified ${ }^{2}$, according to the deposition density expressed in $\mathrm{kBq} \mathrm{m}^{-2}$ and the potential average annual effective dose expressed in $\mathrm{mSv}$ (Table 1 ).

Living in contaminated areas induces both internal and external exposure. The effective dose from external exposure was estimated to be about $0.08 \mathrm{mSv}$ per year in a region with a ${ }^{137} \mathrm{Cs}$ cesium density deposition equal to $37 \mathrm{kBq} \mathrm{m}^{-2}$ (Averin, personal communication); this is consistent with the previously published estimate of $4.8 \mathrm{mSv}$ per year for children living in a region with a density deposition of $2.2 \mathrm{MBq} . \mathrm{m}^{-2}$ (Handl et al., 2003). However, the density deposition is highly variable even within a village, therefore leading to high uncertainties in the dose.

\subsection{Planning of the project}

In the framework of the management of Chernobyl consequences, the Belarusian authorities initiated a public health program for children from 3 to 17 years old living in contaminated areas based on "sanitation", i.e. periodic stays in a sanatorium with, in particular, provision of "clean" food, the frequency being usually once a year. A check-up is systematically performed before departure to the sanatorium in order to adapt care for each child. This check-up includes a basic medical examination and an evaluation of the ${ }^{137} \mathrm{Cs}$ body burden. In the Chechersk district, it was operated by the hospital.

The partners of this project decided to complete this medical check-up to assess the global health status of the children. In order to define the protocol of the medical examinations, meetings were organized with French pediatricians and physicians from Chechersk hospital. The study population comprised all children from the district included in the public health program, with no additional criteria of inclusion.

\subsection{Data collection}

Three sets of data were collected during three series, in 2005-2006, 2007 and 2008-2009. Some parameters were registered to characterize each child: an individual code, gender and age, place of birth, place of residence (urban/rural), duration of residence in the district, and radioactive zone of residence according to Table 1 . To assess eating behavior, a list of the most common foods was established: (1)-potato, (2)-other vegetables, (3)-fruit, (4)-berries, (5)-mushrooms, (6)-meat, (7)-lard, (8)-fish, (9)-eggs, (10)-dairy products, (11)-other products, and frequency was established by a questionnaire.

Living conditions were assessed as good, satisfactory or unsatisfactory by a district commission, taking into account the family income, parents' care, etc.

${ }^{2}$ Law of the Republic of Belarus "On legal regime of territories contaminated as a result of the Chernobyl accident" as of November 12, 1991 No. 1227-XII. 


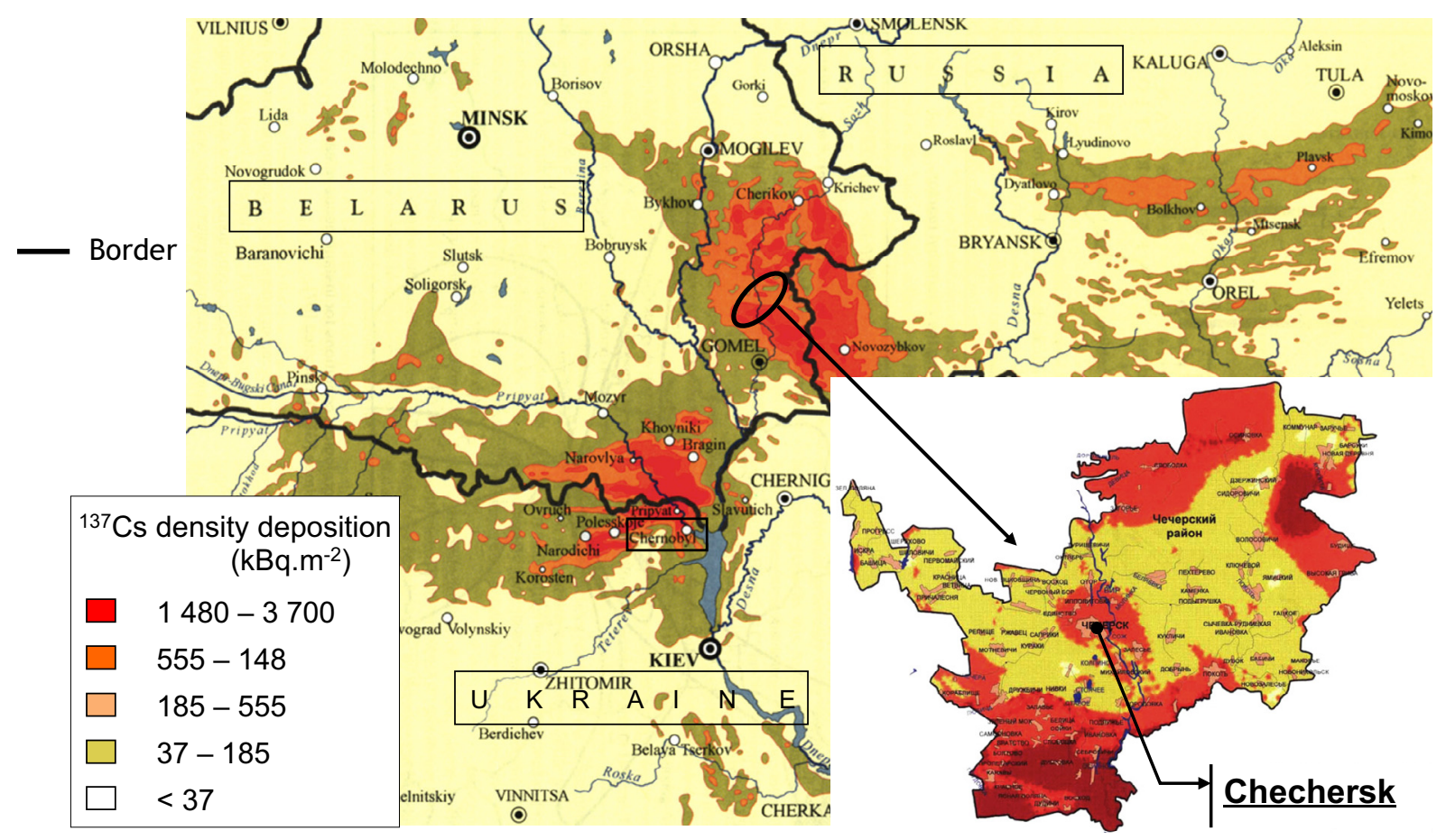

Figure 1. Map of ${ }^{137} \mathrm{Cs}$ deposition density expressed in $\mathrm{kBq} \mathrm{m}^{-2}$ in the west part of Belarus and in the Chechersk district (partly from UNSCEAR (2008), Annex D p. 91 and from the Atlas of cesium contamination of Europe after the Chernobyl accident, Office for Official Publications of the European Communities (1998)).

Table 1. Definition of radioactive zones of residence in Belarus according to the deposition density and average annual effective dose (over the natural and technogenic background) for inhabitants.

\begin{tabular}{lcccc} 
Zone & \multicolumn{3}{c}{ Deposition density $\left(\mathbf{k B q ~ m}^{-\mathbf{2}}\right)$} & $\begin{array}{c}\text { Average annual } \\
\text { effective dose }\end{array}$ \\
\hline $\mathrm{A}$ & $37-185$ & $5.55-18.5$ & $0.37-0.74$ & $<1 \mathrm{mSv}$ \\
$\mathrm{B}$ & $<185$ & $<18.5$ & $<0.74$ & Possibly $>1 \mathrm{mSv}$ \\
$\mathrm{C}$ & $185-370$ & $18.5-46.3$ & $0.74-1.85$ & Possibly $>1 \mathrm{mSv}$ \\
$\mathrm{D}$ & $370-555$ & $46.3-74.0$ & $0.74-1.85$ & Possibly $>1 \mathrm{mSv}$ \\
$\mathrm{E}$ & $555-1,480$ & $74.0-111.0$ & $1.85-3.7$ & Possibly $>5 \mathrm{mSv}$ \\
\hline
\end{tabular}

Medical examinations were performed by hospital physicians, with support from experts of the Republican Research Center for Radiation Medicine and Human Ecology (RRCRM\&HE). They were carried out with parental consent and respecting the Belarusian law $^{3}$ and rules of ethics. This clinical check-up allowed determining morbidity; for instance, the presence of diseases or dysfunctions. Several health indicators were recorded, such as the global health status and the physical and psychomotor development. In total, approximately 30 parameters were recorded for every child for each check-up.

The internal content of ${ }^{137} \mathrm{Cs}$ was measured by whole-body counting with a scintillation detector (Atomtex ${ }^{\circledR}$ ) at the hospital. This apparatus was verified at regular intervals and calibration was checked every day with a ${ }^{137} \mathrm{Cs}$ source. Measurements

\footnotetext{
${ }^{3}$ Order of the Ministry of Health of the Republic of Belarus of 11.08.2003 N 140 "On conducting medical examination of children living in rural areas and urban settlements of district subordination".
}

were usually carried out on the same day as the medical examination. Results were expressed in $\mathrm{Bq} \mathrm{kg}^{-1}$.

\subsection{Definition of health indicators considered}

Physical development: this is an indicator classically used by physicians. Codification was based on Machulina and Galkevich (2004), according to different criteria (height, weight, etc.). Three groups were defined by comparison with standard values: accelerated, normal or delayed development.

Global health status: this is a local indicator classically used by Belarusian physicians. Codification was based on Machulina and Galkevich (2004). Taking into account different parameters (physical and psychological development, heart and breath rates, blood pressure, frequency of diseases, chronic disease(s), behavior), children were classified into 4 health groups: from I for children in good health to IV for children in the least good health. In the present analyses, the 3rd and 4th groups were pooled because of low numbers of children. 
Table 2. Evolution of the age distribution of children (in percentage) with check-up series, per gender.

\begin{tabular}{|c|c|c|c|c|c|c|c|c|c|c|c|c|}
\hline Age & \multicolumn{2}{|c|}{$<7$ years } & \multicolumn{2}{|c|}{ [7-9 years [ } & \multicolumn{2}{|c|}{ [9-11 years[ } & \multicolumn{2}{|c|}{ [11-13 years[ } & \multicolumn{2}{|c|}{ [13-15 years[ } & \multicolumn{2}{|c|}{$>15$ years } \\
\hline $\begin{array}{ll}\text { Series } & \text { Gender }\end{array}$ & Male & Female & Male & Female & Male & Female & Male & Female & Male & Female & Male & Female \\
\hline 1 & 28 & 28 & 16 & 15 & 15 & 18 & 23 & 22 & 17 & 15 & 1 & 1 \\
\hline 2 & 19 & 20 & 16 & 15 & 15 & 15 & 19 & 20 & 22 & 22 & 10 & 9 \\
\hline 3 & 7 & 10 & 13 & 11 & 15 & 15 & 14 & 15 & 20 & 20 & 31 & 30 \\
\hline
\end{tabular}

Thyroid modifications: this bimodal indicator groups together a wide range of thyroid dysfunctions, such as diffuse or nodular goiter or thyroiditis.

Cardiac dysfunctions: this bimodal indicator groups together a wide range of cardiac dysfunctions, such as functional cardiopathy, myocardiodystrophy or mitral valve prolapse.

\subsection{Data analysis}

A data sheet was created to record information during check-ups. Data were codified to facilitate analysis. For children born outside of the district, the duration of residence in the district replaced the age parameter.

The analysis and interpretation of results were performed in two steps. The first step allowed validating the data, identifying the necessary precision for further analysis, determining the most relevant parameters and obtaining the first results. Then, a dialogue was held with parents, teachers and healthcare professionals from the district, in order to present and discuss the first results, and discuss their expectations for further analysis. The most frequent questions had to do with the influence of the deposition density, cesium body burden, living conditions, etc. Therefore, the aim of the second step of analysis was to look for relations between parameters. Data analysis was shared between Belarusian, Norwegian and French partners. The level of the ${ }^{137} \mathrm{Cs}$ body burden was analyzed according to age, rural or urban residence, radioactive zone of residence, living conditions, eating habits, and the period of the year when the whole-body counting was performed. Analyses were performed after log-transformation of the variable. The health indicators were analyzed according to several parameters: living conditions, age, residence, eating habits, radioactive zone and internal ${ }^{137} \mathrm{Cs}$ burden. The radioactive zone of living can reflect both external and internal exposure in a long range, but does not take into account individual comportment. The ${ }^{137} \mathrm{Cs}$ body burden is a precise measurement of internal exposure, but at a certain time, so it may not reflect long-term exposure.

These analyses focused on the group of children who underwent 3 successive medical examinations.

Because of the large number of parameters considered, multivariate analyses (analysis of variance and categorical data modeling) were conducted for some endpoints to verify if the associations observed in univariate analyses persisted when several factors were considered simultaneously. The resulting $P$-values are useful to rank the relative impact of each independent factor in the variations of a specific health indicator. As no a priori hypotheses were determined in the protocol of the study, their interpretation as indicators of statistically significant associations may be erroneous. All analyses were carried out with the SAS statistical package.

\section{Results}

The results are presented in 5 sections: description of the data set, characteristics of the group of children, ${ }^{137} \mathrm{Cs}$ body burden, analysis of some health indicators and discussion of the results with stakeholders.

\subsection{Description of the data set}

Three series of check-ups were performed between 2005 and 2009. For each of the 3 series, a check-up was performed for about 2,500 children, i.e. about $90 \%$ of the total number of children living in the district. Approximately $95 \%$ of these children benefited from 3 check-ups.

Data from the 2,395 children having undergone 3 medical examinations (denominated hereafter as the group of children) were further analyzed when looking for relations between parameters.

\subsection{Characteristics of the group of children}

The group of children included $53 \%$ boys and $47 \%$ girls. The age increased with the series; as an example, the percentage of children below 7 years old decreased from $28 \%$ in the 1 st series to about $8 \%$ in the $3 \mathrm{rd}$ one, while the percentage of children over 15 years old increased from about $1 \%$ in the first series to about $30 \%$ in the 3 rd one (Table 2 ).

$1,388(58 \%)$ children lived in the town of Chechersk, and 1,007 (42\%) in rural localities. Concerning radioactive zoning, Chechersk city was in zone $\mathrm{C}$ and the distribution for rural children was as follows: $187(7.8 \%)$ in zone A, $92(3.8 \%)$ in zone B, $648(27 \%)$ in zone C, $62(2.6 \%)$ in zone D and 18 $(0.8 \%)$ in zone E. Because of the small number of children living in zone $\mathrm{E}$, the results from zones $\mathrm{D}$ and $\mathrm{E}$ were pooled for further analysis.

The distribution of children according to the living conditions and radioactive zone is presented in Table 3. Living conditions were different among areas of residence, with $6 \% \mathrm{vs}$. $16 \%$ in unsatisfactory conditions, respectively, for urban and rural children. In the rural group, the percentage of children with unsatisfactory living conditions increased from $11 \%$ in radioactive zone $\mathrm{A}$ to $31 \%$ in radioactive zones $\mathrm{D}+\mathrm{E}$.

Eating habits were slightly different between urban and rural children, but the most important variations were related to living conditions. Compared with children with good or satisfactory living conditions, children in unsatisfactory living conditions had lower consumption of fruits, berries, meat, fish, lard and eggs. A decrease in dairy product consumption was also observed, but to a lower extent. Their diet was much less diversified, with mainly potatoes and vegetables. 
Table 3. Distribution of children (in percentage) according to the living conditions, area of residence and radioactive zone.

\begin{tabular}{|c|c|c|c|c|c|}
\hline \multirow{2}{*}{ Residence } & \multirow{2}{*}{ Radioactive zone } & \multicolumn{3}{|c|}{ Living conditions } & \multirow{2}{*}{ Number of children } \\
\hline & & Good & Satisfactory & Unsatisfactory & \\
\hline All & All & 21.5 & 68.1 & 10.4 & 2,395 \\
\hline Urban & Zone C & 24.1 & 69.9 & 6.1 & 1,388 \\
\hline Rural & All & 18.0 & 65.6 & 16.4 & 1,007 \\
\hline \multirow{4}{*}{ Rural } & Zone A & 15.0 & 73.8 & 11.2 & 187 \\
\hline & Zone B & 33.7 & 52.2 & 14.1 & 92 \\
\hline & Zone C & 17.0 & 66.7 & 16.4 & 648 \\
\hline & Zones D + E & 15.0 & 53.8 & 31.3 & 80 \\
\hline
\end{tabular}

Table 4. Distribution of the ${ }^{137} \mathrm{Cs}$ body burden (in percentage) for the 3 series of data.

\begin{tabular}{lccc}
\hline Range of values $(\mathbf{B q ~ k g}$ & \\
\hline$<10$ & Series $\mathbf{1}$ & Series 2 & Series 3 \\
\hline $10-20[$ & 47.4 & 43.5 & 69.7 \\
{$[20-50[$} & 23.3 & 23.8 & 14.7 \\
{$[50-100[$} & 19.7 & 21.5 & 10.8 \\
$>100$ & 7.6 & 8.2 & 3.5 \\
Average value $\left(\mathrm{Bq} \mathrm{kg}^{-1}\right)$ & 1.9 & 2.9 & 1.2 \\
Maximum value $\left(\mathrm{Bq} \mathrm{kg}^{-1}\right)$ & 20.6 & 42.2 & 11.8 \\
\hline
\end{tabular}

\section{3 $\quad{ }^{137}$ Cs body burden}

Table 4 presents the results of body burden analyzed for the 3 series. Due to some lack of data, especially in the 3rd series, the analyses relied only on 1,714 children for which 3 successive measurements were available. First, it is important to note that whole-body counting gives a result which is very sensitive to the radioactive contamination of food recently consumed; therefore, individual results can vary drastically from one series to another. For instance, for one child (a girl, 11 years old in 2005, zone C), the ${ }^{137} \mathrm{Cs}$ body burden was equal to $122 \mathrm{~Bq} \mathrm{~kg}^{-1}$ in 2005, 19,326 Bq kg $\mathrm{in}^{-1} 007$ and below the detection level in 2009.

Internal contamination appeared rather low, with about $50 \%$ of the children having less than $10 \mathrm{~Bq} \mathrm{~kg}^{-1}$ and only a few percent of the children with more than $100 \mathrm{~Bq} \mathrm{~kg}^{-1}$.

The percentage of children with a ${ }^{137} \mathrm{Cs}$ burden above $50 \mathrm{~Bq} \mathrm{~kg}^{-1}$ was about $10 \%$ for the first 2 series and less than $5 \%$ in the third one. It increased with age; when comparing children below 7 years old and children above 13 years old, it increased, respectively, by about $60 \%$ for urban children and $80 \%$ for rural ones.

For further analysis, the results of the 3 series were pooled and classified into three groups according to the ${ }^{137} \mathrm{Cs}$ body burden. The distribution for all children was: $72 \%$ below 20 , $19 \%$ between 20 and 50 , and $9 \%$ above $50 \mathrm{~Bq} \mathrm{~kg}^{-1}$; values were similar for girls and boys. This distribution differed according to the area of residence, with a higher ${ }^{137} \mathrm{Cs}$ body burden for rural children than for urban ones (Table 5).

The results of the ${ }^{137} \mathrm{Cs}$ burden in relation to the area of residence and radioactive zone are presented in Table 4 . When comparing children living in the same radioactive zone $(\mathrm{C})$, the percentage of children with more than $50 \mathrm{~Bq} \mathrm{~kg}^{-1}$ in the rural areas was almost twice (15\%) that in the urban one $(8 \%)$. For rural children, it was possible to analyze internal contamination in relation to radioactive zones. In zone A, nearly $97 \%$
Table 5. Distribution of children (in percentage) according to the ${ }^{137} \mathrm{Cs}$ burden, area of residence and radioactive zone.

\begin{tabular}{lcccc}
\hline \multirow{2}{*}{ Residence } & \multirow{2}{*}{ Radioactive zone } & \multicolumn{3}{c}{$\mathbf{1 3 7}^{\mathbf{C}} \mathbf{C s}$ body burden $\left(\mathbf{B q ~} \mathbf{~ k g}^{-\mathbf{1}}\right)$} \\
& & $\mathbf{2 0}$ & $\mathbf{2 0 - 5 0}$ & $\mathbf{> 5 0}$ \\
\hline All & All & 72.0 & 18.8 & 9.1 \\
Urban & Zone C & 76.7 & 15.5 & 7.8 \\
Rural & All & 65.6 & 23.5 & 11.0 \\
& Zone A & 96.5 & 2.8 & 0.7 \\
& Zone B & 59.6 & 30.9 & 9.5 \\
Rural & Zone C & 54.7 & 30.3 & 15.0 \\
& Zones D + E & 81.5 & 14.6 & 3.8 \\
\hline
\end{tabular}

Table 6. Distribution of children (in percentage) according to the ${ }^{137} \mathrm{Cs}$ burden, area of residence and living conditions.

\begin{tabular}{lcccc}
\hline \multirow{2}{*}{ Residence } & \multirow{2}{*}{ Living conditions } & \multicolumn{4}{c}{ Cs body burden $\left(\mathbf{B q ~} \mathbf{~ k g}^{-1}\right)$} \\
& & $<\mathbf{2 0}$ & $\mathbf{2 0 - 5 0}$ & $\mathbf{> 5 0}$ \\
\hline \multirow{3}{*}{ Urban } & Good & 79.8 & 12.1 & 8.2 \\
& Satisfactory & 76.0 & 16.2 & 7.8 \\
& Unsatisfactory & 72.4 & 21.1 & 6.5 \\
\multirow{2}{*}{ Rural } & Good & 66.0 & 25.7 & 8.3 \\
& Satisfactory & 66.2 & 22.7 & 11.1 \\
& Unsatisfactory & 62.3 & 24.2 & 13.5 \\
\hline
\end{tabular}

of children were below $20 \mathrm{~Bq} \mathrm{~kg}^{-1}$ of ${ }^{137} \mathrm{Cs}$, and less than $1 \%$ were above $50 \mathrm{~Bq} \mathrm{~kg}^{-1}$. For children in zones $\mathrm{B}$ and $\mathrm{C}$, internal contamination increased, with about $30 \%$ of children in the $20-50 \mathrm{~Bq} \mathrm{~kg}^{-1}$ category and 10 or $15 \%$ above $50 \mathrm{~Bq} \mathrm{~kg}^{-1}$ in zone $\mathrm{B}$ or $\mathrm{C}$, respectively. However, the percentage of children above $50 \mathrm{~Bq} \mathrm{~kg}^{-1}$ was lower in zones $\mathrm{D}+\mathrm{E}$ than in zones $\mathrm{B}$ and $\mathrm{C}$, and even lower than in the urban area $(\mathrm{C})$.

Internal exposure appeared to be related to living conditions, but differently for urban and rural children (Table 6). When comparing good and unsatisfactory living conditions, the percentage of children above $50 \mathrm{~Bq} \mathrm{~kg}^{-1}$ increased from $8.3 \%$ to $13.5 \%$ for rural children, whereas it decreased slightly from $8.2 \%$ to $6.5 \%$ in the urban zones.

The influence of food consumption was evaluated. Firstly, the results of measurements were compared according to the time of the year when they were performed. As stays in a sanatorium are most frequently organized in spring and summer, about $70 \%$ of measurements were performed between January and June, while only about $7 \%$ were performed between July and September and nearly 24\% from October to December. No trend with the month was observed; maximum and minimum average values were observed, respectively, in January 
Table 7. Distribution of children (in percentage) according to the health group, area of residence and living conditions.

\begin{tabular}{lcccc}
\multirow{2}{*}{ Residence } & \multirow{2}{*}{ Living conditions } & \multicolumn{3}{c}{ Health group } \\
& & Group I & Group II & Groups III-IV \\
\hline All & All & 19.3 & 65.4 & 15.3 \\
Urban & All & 17.6 & 63.3 & 19.1 \\
Rural & All & 21.7 & 68.2 & 10.0 \\
& Good & 16.8 & 59.3 & 24.0 \\
Urban & Satisfactory & 18.6 & 63.5 & 17.9 \\
& Unsatisfactory & 9.5 & 77.4 & 13.1 \\
& Good & 24.3 & 63.0 & 12.7 \\
Rural & Satisfactory & 23.0 & 67.5 & 9.5 \\
& Unsatisfactory & 13.9 & 77.0 & 9.1 \\
\hline
\end{tabular}

Group I: good health (without noticeable deviation), Group II: with deviations, Groups III and IV: noticeable chronic disease or with recurrent symptoms.

Table 8. Distribution of children (in percentage) according to physical development, area of residence and living conditions.

\begin{tabular}{lcccc}
\hline & & \multicolumn{3}{c}{ Physical development } \\
& & Accelerated & Normal & Delayed \\
\hline \multirow{3}{*}{ Residence } & All & 0.7 & 95.4 & 4.0 \\
& Urban & 0.6 & 97.0 & 2.4 \\
& Rural & 0.8 & 93.1 & 6.0 \\
Living conditions & Good & 0.4 & 99.0 & 0.6 \\
& Satisfactory & 0.4 & 96.9 & 2.7 \\
& Unsatisfactory & 2.8 & 77.9 & 19.3 \\
\hline
\end{tabular}

and June for the 1st series, April and January for the 2nd series and March and December for the 3rd one; the results obtained between November and April, with winter types of food, were then compared with those performed between May and October, with more fresh food: they were similar. Secondly, the relation between the results of whole-body counting and different food consumption was assessed. The only noticeable difference was observed with mushrooms, with the average ${ }^{137} \mathrm{Cs}$ body burden equal to $13.4 \mathrm{~Bq} \mathrm{~kg}^{-1}$ among non-consumers and $20.7 \mathrm{~Bq} \mathrm{~kg}^{-1}$ among consumers.

Considered simultaneously in a multivariate analysis, the age, gender, living conditions, area of residence (urban/rural), mushroom consumption and radioactive zone were independently related to the ${ }^{137} \mathrm{Cs}$ body burden $(p<0.0001)$. Considering their relative importance in the explanation of the variance of the ${ }^{137} \mathrm{Cs}$ body burden, the ranking was first the area of residence, second the radioactive zone and the consumption of mushrooms, and third the age, gender and living conditions.

\subsection{Analysis of some health indicators}

\subsubsection{Global health status}

The results, presented in Table 7 , showed that $19 \%$ of all children were in good health, $65 \%$ had deviations and $15 \%$ had chronic disease. The percentage of children in good health was higher in rural $(21.7 \%)$ than in urban areas (17\%). The variation in living conditions was similar in rural and urban areas; going from good to unsatisfactory, the percentages of children in good health (group I) or with chronic disease (groups IIIIV) decreased, whereas the percentage of children with deviations (group II) increased. No relation to the radioactive zone was observed. In rural areas, the percentage of children in groups III-IV was respectively $13.4 \%, 8.7 \%, 9.3 \%$ and $10 \%$ in zones $\mathrm{A}, \mathrm{B}, \mathrm{C}$ and $\mathrm{D}+\mathrm{E}$.

\subsubsection{Physical development}

Physical development was diagnosed as normal for $95 \%$, and delayed for only $4 \%$ of the children (Table 8 ). The percentage of children with developmental delay was higher for rural than for urban children, with, respectively, $6 \%$ and about $2 \%$. It increased drastically with decreasing living conditions, with less than $1 \%$ for children in good living conditions and $19 \%$ for children in unsatisfactory conditions. No relation to the radioactive zone was observed; in rural areas, the percentage of children with delayed development was $5 \%$ in zones $\mathrm{D}+\mathrm{E}$, i.e. similar to zone $\mathrm{B}(5.4 \%)$ and lower than in zone C $(7.4 \%)$.

Multivariate analysis confirmed the strong association of physical development with the living conditions $(p<0.0001)$ and, to a lesser extent, with urban/rural residence $(p=0.005)$. Physical development did not appear to be associated with the radioactive zone $(p=0.14)$ or ${ }^{137} \mathrm{Cs}$ body burden $(p=0.85)$.

\subsubsection{Thyroid modifications}

The results are presented in Tables 9 and 10. Only 9\% of all children had thyroid modifications, which were diffuse goiter $(82.4 \%)$, nodular goiter $(0.9 \%)$ and autoimmune thyroiditis (1-2\%). The percentage was higher for rural than for urban areas with, respectively, about $11 \%$ and $8 \%$.

In Table 9, the variation in living conditions seems to be opposite in rural and urban areas; in rural areas the percentage 
Table 9. Distribution (in percentage) of children with or without thyroid modifications and with or without cardiac dysfunctions, according to the area of residence and living conditions.

\begin{tabular}{lccccc}
\hline \multirow{2}{*}{ Residence } & \multirow{2}{*}{ Living conditions } & \multicolumn{2}{c}{ Thyroid modifications } & \multicolumn{2}{c}{ Cardiac dysfunctions } \\
& & No & Yes & No & Yes \\
\hline All & All & 91.0 & 9.0 & 88.0 & 12.0 \\
Urban & All & 92.2 & 7.8 & 85.5 & 14.5 \\
Rural & All & 89.3 & 10.7 & 91.4 & 8.6 \\
& Good & 90.4 & 9.6 & 83.2 & 16.8 \\
\multirow{3}{*}{ Urban } & Satisfactory & 92.8 & 7.2 & 85.7 & 14.3 \\
& Unsatisfactory & 92.9 & 7.1 & 92.9 & 7.1 \\
& Good & 91.2 & 8.8 & 88.4 & 11.6 \\
\multirow{2}{*}{ Rural } & Satisfactory & 89.7 & 10.3 & 91.7 & 8.3 \\
& Unsatisfactory & 85.5 & 14.5 & 93.3 & 6.7 \\
\hline
\end{tabular}

Table 10. Distribution (in percentage) of children with or without thyroid modifications and with or without cardiac dysfunctions, according to the area of residence and radioactive zone.

\begin{tabular}{cccccc}
\hline \multirow{2}{*}{ Area } & \multirow{2}{*}{ Radioactive zone } & \multicolumn{2}{c}{ Thyroid modifications } & \multicolumn{2}{c}{ Cardiac dysfunctions } \\
& & No & Yes & No & Yes \\
\hline Urban & Zone C & 92.2 & 7.8 & 84.9 & 15.1 \\
Rural & All & 89.3 & 10.7 & 90.5 & 9.5 \\
& Zone A & 90.4 & 9.6 & 91.4 & 8.6 \\
\multirow{3}{*}{ Rural } & Zone B & 92.4 & 7.6 & 94.6 & 5.4 \\
& Zone C & 89.2 & 10.8 & 90.0 & 10.0 \\
& Zones D + E & 83.8 & 16.2 & 87.5 & 12.5 \\
\hline
\end{tabular}

of children with thyroid modifications increased with decreasing living conditions, whereas it slightly decreased in urban areas. Nevertheless, an impact of living conditions on thyroid modifications does not persist in multivariate analysis.

Multivariate analysis showed an association with age $(p<0.0001)$ and, to a lesser extent, with gender $(p<0.01)$, but little association was observed with the radioactive zone $(p=0.09)$ or ${ }^{137} \mathrm{Cs}$ body burden $(p=0.15)$.

\subsubsection{Cardiac dysfunctions}

Cardiac dysfunctions, such as functional cardiopathy $(51.5 \%)$, myocardiodystrophy $(3.3 \%)$ and mitral valve prolapse $(29.8 \%)$, were identified in $12 \%$ of the children. The results are presented in Tables 9 and 10. The percentage of cardiac dysfunctions was about $50 \%$ higher for urban children than for rural ones; it was also about $50 \%$ higher for children living in good conditions compared with those living in unsatisfactory conditions.

For cardiac dysfunctions, multivariate analysis showed a positive association with age $(p<0.0001)$ and, to a lesser extent, with gender, living conditions and mushroom consumption $(p<0.01)$ and area of residence $(p=0.025)$. Cardiac dysfunctions did not appear to be associated with the radioactive zone $(p=0.24)$ or ${ }^{137} \mathrm{Cs}$ body burden $(p=0.88)$.

\subsection{Discussion of results with stakeholders}

The results were regularly discussed with the partners of the project. Finally, they were presented and discussed with regional health professionals and representatives of the authorities, during a seminar organized in the Republican Research Center of Radiation Medicine and Human Ecology
(RRCRM\&HE). The physicians of Chechersk hospital were in charge of informing parents individually about their children's health and district inhabitants about global results.

\section{Discussion}

\subsection{Aims of the study}

This project was initiated to provide a description of the health status of a child population living in an area contaminated after the Chernobyl accident. Children included were born at least several years after the accident, and therefore were only exposed to long-lived radionuclides.

The aim was to describe the ${ }^{137} \mathrm{Cs}$ body burden and the frequency of development and health indicators simultaneously with the characterization of environmental and lifestyle parameters, in a well-defined child population. It was neither to identify any potential radiation-induced effects nor to demonstrate a dose-risk relationship. No a priori hypothesis was defined about the potential association between health indicators and environmental and lifestyle parameters.

\subsection{Advantages and limitations of the study}

This study is almost exhaustive, including nearly all children in a district. Also, the migration rate in the district was very low during the study period, which explains why a large majority of the children attended the 3 check-up series. Furthermore, the absence of pathology was verified for the children who did not benefit from a check-up. This feature of 
the study is very important, as it allows evaluating the prevalence of development and health indicators in a whole district, with limited possibility of selection bias. Furthermore, the repetition of check-ups over a few years in the same population allowed confirming the observed results. The rather large number of children who underwent three successive medical check-ups provided a good basis in order to perform a systematic description of the variation of development and health indicators with multiple geographical and socioeconomic parameters.

The results for only a few indicators are presented here. Detailed analysis related to anemia has been presented elsewhere (Zhunussova et al., 2013).

Dialogue meetings with parents were set up to discuss the results of check-ups. Health professionals are now sensitive to screening of some dysfunctions/pathologies and, since the material was provided, they now have better conditions to diagnose and treat them as needed.

The efforts made by the authorities for economic development and the prospect of better living conditions and eating habits should also contribute to improving the health of the children.

A limitation comes from the fact that the numbers are low when considering specific categories such as, for instance, the number of children living in zones D and E. This fact and the strong interactions between living conditions and radioactive zones in rural areas have to be taken into account when looking for relation of various parameters to radioactive zones.

Another limitation of the project is that it is only descriptive, with no attempt to identify causes and evaluate consequences. As an example, the study did not include measurement of urinary iodine to assess the possible relation between thyroid modification and iodine deficiency, and too few measurements of thyroid-stimulating hormone (TSH) were performed to evaluate possible thyroid function deficiency. However, it should be noted that local health professionals took care of modifications/dysfunctions identified throughout the project.

No a priori hypotheses were determined when launching the study, and the limited size of the study would not have allowed for enough statistical power to quantify exposure-risk relationships. Given the large amount of information collected, using statistical tests to identify a posteriori specific associations would have been erroneous and would have led to misleading interpretations. Therefore, $P$-values resulting from multifactorial analyses are useful to rank the relative impact of each independent factor, and must not be interpreted as indicators of statistically significant associations.

The systematic medical examinations were performed with no reference to international standards. Especially, they may have revealed asymptomatic dysfunctions, leading to high frequency. We consider that the frequencies observed are adequate for comparison between groups inside the study, but can hardly be compared with an external reference. Initially, it was planned to perform check-ups with the same protocol for children living in a district with low contamination, such as Vitebsk in the north of the country; however, it finally proved impossible to do this.
Some of the evaluated health indicators are local indicators, since the aim of the project was to provide information to parents and health professionals, and comparison of the results with the literature may sometimes be difficult.

\subsection{Internal exposure}

Our results confirmed the high variability of the ${ }^{137} \mathrm{Cs}$ body burden between successive individual measurements. This point is clearly illustrated by the example of a young girl for whom the ${ }^{137} \mathrm{Cs}$ body burden varied by more than a factor of 100 between 2 successive measurements. Measurement results are influenced by the type and quality of food consumed in the few weeks before measurement. Therefore, it was decided not to calculate the annual committed effective dose from one single ${ }^{137} \mathrm{Cs}$ body burden measurement. If the ${ }^{137} \mathrm{Cs}$ body burden was constant, $100 \mathrm{~Bq} \mathrm{~kg}^{-1}$ would correspond to an annual committed effective dose of $0.2 \mathrm{mSv}$ for children below 15 years old and $0.3 \mathrm{mSv}$ for older ones.

It is important to take into account uncertainties, especially in low values, when interpreting the results.

Nevertheless, the results show that, despite the fact that Chechersk district is one of the most contaminated in Belarus, internal contamination is low on average. This is probably due to the State recovery program for management of Chernobyl consequences: radiation monitoring and countermeasures in local private or collective agriculture. In the scientific literature, results are rarely expressed as the body burden $\left(\mathrm{Bq} \mathrm{kg}^{-1}\right)$, but most often as the committed effective dose. The results of the present study are lower than previously described; measurements performed in the Gomel region, between May 1991 and April 1996, on about 19,000 children, 0-10 years old at the time of the accident, showed that about $75 \%$ of children had less than $50 \mathrm{~Bq} \mathrm{~kg}^{-1}$ and about $8 \%$ had more than $100 \mathrm{~Bq} \mathrm{~kg}^{-1}$ (Yamashita and Shibata, 1997), whereas the values are respectively about $90 \%$ and 1 to $3 \%$ in this study. This could be explained by the period of 10 to 15 years between the 2 studies, with increasing efficacy of countermeasures.

When looking for a relation to nutrition habits, the ${ }^{137} \mathrm{Cs}$ body burden is only related to consumption of mushrooms, which were previously described as the most important contributors to radioactivity intake (Handl et al., 2003).

A higher internal ${ }^{137} \mathrm{Cs}$ burden was observed in rural than in urban children. This may be in relation to a larger consumption of home-grown products in rural areas. In rural families with unsatisfactory living conditions, less care is probably given to both the nutritional and radiological quality of food, which could explain the higher percentage of children with over $50 \mathrm{~Bq} \mathrm{~kg}^{-1}$.

A study, based on data collected from different regions near Chernobyl, concluded the existence of a significant positive correlation between the body burden and deposition density, while noting contradictory results in some regions such as Gomel (Yamashita and Shibata, 1997). In this study, the results of internal exposure are lower for rural children living in zones $\mathrm{A}$ and $\mathrm{D}+\mathrm{E}$ than for those living in zones $\mathrm{B}$ and $\mathrm{C}$; this could be due to a lower probability of exposure in zone A and greater attention paid to food contamination in zones with high density deposition than in zones with medium-range density deposition. 
Some reports indicate that ${ }^{90} \mathrm{Sr}$ contamination could contribute to internal exposure (Averin, personal communication). However, no evaluation was performed in this study, as Chechersk district is situated in the northern part of the Gomel region, i.e. rather far from Chernobyl NPP, and because of the complexity of measurements.

\subsection{Development and health indicators}

The results, rather similar among the 3 series, suggested that the situation was stable, with no worsening.

This study shows that living conditions and, to a lesser extent, area of residence (rural/urban) are the major determinants for child development. This observation is in agreement with previously published results, as an inverse relation between development and socio-economic status is frequently described (Pillas et al., 2014).

No thyroid cancer was diagnosed, which could be expected since this disease is rare in children and all the children in this study were born many years after the accident.

Thyroid modifications could not be related to radioactive iodines, because of their short half-life. The percentage of children diagnosed with goiter in Chechersk district was slightly higher than reported in a previous study, but for all Gomel region (Hatch et al., 2011).

A previous study, performed in the mid-90s on children $0-14$ years old who were affected by the consequences of the Chernobyl accident, already reported high incidences of endocrine diseases in Belarus (Lomat et al., 1997). Frequencies were lower than in the present study, which could have revealed dysfunctions without health impact because of systematic check-ups.

It is interesting to note that, in the present study, cardiac dysfunctions are more frequent in urban than in rural areas and for children in good living conditions, but without any correlation with the ${ }^{137} \mathrm{Cs}$ density deposition or body burden.

\section{Conclusion}

This project was carried out in a highly contaminated district of Belarus in order to provide information to parents. It was based on systematic and complete medical check-ups, not focused on identified radiation-induced health effects. The results provide information about the health status and internal exposure of children living in a contaminated area more than 20 years after the Chernobyl accident. It showed no relation between the development or health indicators considered and the radioactive density deposition or ${ }^{137} \mathrm{Cs}$ body burden.

Due to a small number in some specific groups of children and complex interrelationships among various factors such as living conditions, place of residence and radioactive density deposition, interpretation of the results must be made with caution.
Acknowledgements. This project was subsidized by the IRSN and NRPA; it was integrated in a larger project, which was also subsidized by the French Nuclear Safety Authority (ASN). The authors wish to thank everyone involved in this project for technical, scientific or administrative contributions, as well as for interpreting and translation. They also wish to thank T. Schneider for his careful read-through of this paper.

\section{References}

CORE (2004) Co-operation for Rehabilitation of living conditions in Chernobyl affected areas in Belarus, Programme Declaration of principles, http://www.osce.org/minsk/32088.

Handl J. et al. (2003) Evaluation of radioactive exposure from ${ }^{137} \mathrm{Cs}$ in contaminated areas of northern Ukraine, Health Phys. 84 (4), $502-517$.

Hatch M. et al. (2011) Urinary iodine and goiter prevalence in Belarus: experience of the Belarus - American cohort study of thyroid cancer and other thyroid diseases following the Chornobyl nuclear accident, Thyroid 21 (4), 429-437.

Lomat L. et al. (1997) Incidence of childhood disease in Belarus associated with the Chernobyl accident, Environ. Health Perspect. 105 (Suppl6), 1529-1532.

Machulina L.N., Galkevich N.V. (2004) Complex Assessment of Children Health - Workbook Ministry of Health of the Republic of Belarus, State Institution of Higher Education, Belarusian State Medical Academy of Postgraduate Education, Subdepartment of Pediatrics, Minsk.

Pillas D. et al. (2014) Social inequalities in early childhood health and development: a European-wide systematic review, Pediatr. Research 76 (5), 418-424.

UNSCEAR (2008) Sources and effects of Ionizing radiation United Nations Scientific Committee on the Effects of Atomic Radiation. Report to the General Assembly with Scientific Annexes. Annex D: Health effects due to radiation from the Chernobyl accident.

UNSCEAR (2011) Sources and effects of Ionizing radiation United Nations Scientific Committee on the Effects of Atomic Radiation. Report to the General Assembly with Scientific Annexes. VOLUME II, Annex D, Health effects due to radiation from the Chernobyl accident.

Yamashita S., Shibata Y., Eds. (1997) Chernobyl a decade - Findings of the Chernobyl Sasakawa Health and medical cooperation project: ${ }^{137}$ Cs concentration among children around Chernobyl. Excerta medica international congress series 1156.

Zablotska L.B. et al. (2011) Thyroid cancer risk in Belarus among children and adolescents exposed to radioiodine after the Chornobyl accident, Br. J. Cancer 104, 181-187.

Zablotska L.B. et al. (2013) Radiation and the risk of chronic lymphocytic and other leukemias among Chornobyl cleanup workers, Environ. Health Perspect. 121 (1), 59-65.

Zhunussova T. et al. (2013) Anaemia prevalence in children of Chechersk district in Gomel region of the Republic of Belarus contaminated after Chernobyl accident in 1986. In: European Radiation Research Society meeting, Sept 2013, Dublin (Ireland). 